\title{
Accessible Content and Accessibility Experiences: The Interplay of Declarative and Experiential Information in Judgment
}

\author{
Norbert Schwarz \\ University of Michigan
}

\begin{abstract}
Recall tasks render 2 distinct sources of information available: the recalled content and the experienced ease or difficulty with which it can be brought to mind. Because retrieving many pieces of information is more difficult than retrieving only a few, reliance on accessible content and subjective accessibility experiences leads to opposite judgmental outcomes. People are likely to base judgments on accessibility experiences when they adopt a heuristic processing strategy and the informational value of the experience is not called into question. When the experience is considered nondiagnostic, or when a systematic processing strategy is adopted, people rely on accessible content. Implications for the operation of the availability heuristic and the emergence of knowledge accessibility effects are discussed.
\end{abstract}

Judgment researchers have long been fascinated by how minor events may temporarily influence the accessibility of information in memory, which, in turn, may result in pronounced differences in judgment and behavior. In conceptualizing the role of accessible information, researchers have emphasized two different aspects. On the one hand, several related lines of research focused on what comes to mind, that is, the content that is rendered accessible (see Higgins, 1989, 1996; Schwarz, 1995; Wyer \& Srull, 1989). Some of this research showed that we interpret ambiguous information in terms of the applicable concepts that are most accessible at the time (e.g., Higgins, Rholes, \& Jones, 1977). Other research demonstrated that we rarely retrieve all information that may bear on an issue but base our judgments on the subset of relevant information that is most accessible in memory (e.g., Bodenhausen \& Wyer, 1987). In contrast to this emphasis on accessible content, other lines of research focused on how easily something comes to mind, that is, the subjective experience of ease or difficulty of recall. Highlighting the role of subjective accessibility experiences, Tversky and Kahneman's (1973) availability heuristic holds that we form judgments of frequency, likelihood, and typicality on the basis of the ease with which exemplars can be brought to mind. Subsequent lines of research explored the role of ease of retrieval in metacognitive judgments (see Benjamin \& Bjork, 1996; Jacoby \& Kelley, 1987; Kelley \& Jacoby, 1996), including feelings of knowing (e.g., Koriat, 1993), confidence in the accuracy of one's knowledge (e.g., Kelley \& Lindsay,

Requests for reprints should be sent to Norbert Schwarz, Institute for Social Research, University of Michigan, Ann Arbor, MI 48106-1248. E-mail: nschwarz@umich.edu.
1993), or judgments of memory (e.g., Jacoby \& Whitehouse, 1989). In most cases, research into accessibility phenomena has focused either on the role of accessible declarative information or on the role of subjective accessibility experiences.

In this article I extend this research by addressing the interplay of accessible declarative information and subjective accessibility experiences, focusing on the operation of the availability heuristic and the emergence of knowledge accessibility effects in social judgment. In the first section I summarize key theoretical assumptions and highlight the fact that many of the classic experiments are inherently ambiguous, because the obtained effects may reflect differences in what comes to mind as well as differences in how easily it comes to mind. In the subsequent sections I review research that disentangles the distinct influences of accessible content and accessibility experiences and identifies conditions under which people are likely to draw on accessible content versus subjective accessibility experiences in forming a judgment. In the final section I address the theoretical implications of this research for theorizing in social and cognitive psychology.

\section{The Different Faces of Accessibility: Content and Experience}

Psychologists' differential emphasis on accessible content and subjective accessibility experiences is most clearly exemplified in Tversky and Kahneman's (1973) availability heuristic on the one hand and social cognition research into knowledge accessibility effects in social judgment on the other hand. I address both in turn. 


\section{Availability Heuristic}

Tversky and Kahneman's (1973) availability heuristic postulated a metacognitive judgment process: Individuals are assumed to estimate the frequency of an event, or the likelihood of its occurrence, "by the ease with which instances or associations come to mind" ( $p$. 208). Presumably, they monitor their cognitive processes and infer that a given class of events is frequent when relevant exemplars are easy to bring to mind but rare when exemplars are difficult to bring to mind.

Although this heuristic has stimulated an enormous amount of research (see Sherman \& Corty, 1984; Strack, 1985; Taylor, 1982), the classic studies on the issue do not allow strong conclusions about the underlying process. For example, in one of the better known experiments, Tversky and Kahneman (1973, Experiment 3) observed that participants overestimated the number of words that begin with the letter $r$ but underestimated the number of words that have $r$ as the third letter. This finding presumably reflects the fact that words that begin with a certain letter can be brought to mind more easily than words that have a certain letter in the third position. More important, however, this differential ease of recall may influence participants' frequency estimates in two different ways. On the one hand, participants may use the subjective experience of ease or difficulty of recall as a basis of judgment, as suggested by Tversky and Kahneman's (1973) description of the availability heuristic. If so, they would estimate a higher frequency if the recall task was experienced as easy rather than difficult. On the other hand, they may recall as many words of each type as possible within the time allotted to them and may base their judgment on the recalled sample of words. If it was easier to recall words that begin with a certain letter, these words would be overrepresented in the recalled sample, again resulting in an estimate of higher frequency. Note, however, that in the latter case, the estimate would be based on recalled content rather than on the subjective experience of ease of recall. In a related study, Gabrielcik and Fazio (1984) observed that exposing participants to subliminally presented words containing the letter $t$ increased participants' estimates of the frequency of $t$ words. Again, this finding may indicate either that participants could generate more words including a $t$ if primed or that they relied on the ease with which relevant exemplars could be called to mind.

Similar ambiguities apply to other experimental procedures. In another well-known Tversky and Kahneman study (1973, Experiment 8), participants were read two lists of names, one presenting 19 famous men and 20 less famous women and the other presenting 19 famous women and 20 less famous men. When asked, participants reported that there were more men than women in the first list but more women than men in the second list, even though the opposite was the case (by a difference of one). Again, the famous names were presumably easier to recall than the nonfamous ones, resulting in an overestimate. In fact, participants were able to recall about $50 \%$ more of the famous than the nomous names. This difference in actual recall again highlights the ambiguity underlying most tests of the availability heuristic: Are participants' judgments indeed based on the phenomenal experience of ease or difficulty of recall, as Tversky and Kahneman's description of the availability heuristic suggests? Or are their judgments based on the content of recall, with famous names being overrepresented in the recalled sample?

As these examples illustrate, manipulations intended to increase the subjective experience of ease of recall are also likely to affect the amount of recall. In most real-world situations, these two factors are naturally confounded. Unfortunately, this confound renders it difficult to determine whether the obtained estimates of frequency, likelihood, or typicality are based on a metacognitive strategy that draws on individuals' recall experiences or on a biased sample of recalled information. As Taylor (1982) noted, the latter possibility would render the availability heuristic rather trivial-after all, "one's judgments are always based on what comes to mind" (p. 199, italics added). In fact, some textbooks have chosen the latter interpretation in introducing the availability heuristic, as a quote from Medin and Ross (1997) illustrates:

\footnotetext{
The availability heuristic refers to a tendency to form a judgment on the basis of what is readily brought to mind. For example, a person who is asked whether there are more English words that begin with the letter $t$ or the letter $k$ might try to think of words that begin with each of these letters. Because a person can probably think of more words beginning with $t$, he or she would (correctly) conclude that $t$ is more frequent than $\mathrm{k}$ as the first letter of English words. (p. 522)
}

\section{Knowledge Accessibility Effects in Social Judgment}

Similar ambiguities apply to the social judgment literature. This literature has traced many context effects in social judgment to differences in information accessibility (see Bodenhausen \& Wyer, 1987; Higgins, 1989, 1996; Martin \& Clark, 1990; Schwarz, 1995). The underlying assumptions are somewhat different, depending on whether the judgment pertains to a known target, about which information is recalled from memory, or to a new target, about which information is acquired at that time.

When asked to form a judgment about a known target, individuals recall relevant information from memory. However, they do not recall all information that may be relevant to the target but truncate the search process as soon as enough information has come to 
mind to form a judgment with sufficient subjective certainty. As a result, the judgment is dominated by the information that is most accessible at the time. For example, Schwarz, Strack, and Mai (1991) asked respondents to report their general life satisfaction and their marital satisfaction and varied the order in which the questions were presented. When the general life satisfaction question preceded the marital satisfaction question, the reports correlated $r=.32$. When the marital satisfaction question was presented first, however, this correlation increased to $r=.67$. Presumably, answering the marital satisfaction question first rendered information about one's marriage highly accessible and this, rather than other, information was subsequently used in evaluating one's life as a whole (see Schwarz \& Bless, 1992). Accordingly, unhappily married individuals reported lower life satisfaction when the marital satisfaction question was asked first, whereas happily married individuals reported higher life satisfaction under this condition. It remains unclear, however, if effects of this type are solely based on the content that comes to mind. Instead, it is conceivable that the ease with which previously activated content comes to mind may affect the judgment in its own right, either by suggesting that this information is particularly relevant (or else, why would it pop to mind?) or by suggesting that there are many similar features, as implied by the availability heuristic. Hence, the underlying processes may involve a metacognitive component that draws on subjective accessibility experiences.

Similarly, when individuals acquire new information, they are likely to interpret it in terms of the applicable concept that is most accessible at that time. Given that many pieces of information are inherently ambiguous, which concept is brought to bear on them is of crucial importance. For example, Higgins et al. (1977) described a target person with ambiguous behaviors, such as

Once Donald made up his mind to do something it was as good as done, no matter how long it might take or how difficult the going might be. Only rarely did he change his mind, even when it might well have been better if he had.

As expected, their participants inferred from these behaviors either that Donald was stubborn, a negative trait, or that he was persistent, a positive trait, depending on which trait concept had been rendered accessible by a preceding task. Again, it is conceivable that the apparent ease with which a trait concept came to mind while reading the behavioral description contributed to the obtained effect.

\section{Summary}

In sum, different bodies of literature have traced accessibility effects either to what comes to mind or to how easily it comes to mind. Unfortunately, most manipulations that influence what comes to mind are also likely to influence how easily it comes to mind, rendering it difficult to determine the underlying processes. In this article I address this ambiguity. In the next section I review research that demonstrates that subjective accessibility experiences can serve as a source of information in their own right, consistent with the metacognitive proposal entailed in Tversky and Kahneman's (1973) availability heuristic. In the subsequent sections I review research that has created conditions under which reliance on accessible content leads to different judgmental outcomes than reliance on accessibility experiences, thus providing a methodological tool for determining the variables that govern the use of these different sources of information.

\section{Accessibility Experiences as a Source of Information}

If subjective experiences of ease or difficulty of recall serve as a source of information in their own right, their impact should vary as a function of the perceived diagnosticity of the experience, as has been observed for other types of experiential information, such as moods (e.g., Schwarz \& Clore, 1983) or arousal (e.g., Zillman, 1978; see also Schwarz \& Clore, 1996). According to the availability heuristic, we should infer, for example, that there are many words that begin with the letter $t$ if we find it easy to bring relevant examples to mind. This inference is based on the generally correct assumption that it is easier to recall exemplars of a frequent than an infrequent category. Suppose, however, that you have reason to assume that a temporary situational factor renders $t$ words more accessible than might otherwise be the case. If so, the experienced ease of recall may reflect this irrelevant influence rather than the actual frequency of $t$ words. Hence, you may discount the subjective experience as a relevant source of information. Conversely, if you had reason to assume that a temporary situational factor inhibits the recall of $t$ words, but you find them easy to bring to mind nevertheless, the experienced ease of recall should seem particularly diagnostic. The emergence of such discounting and augmentation effects (Kelley, 1972) would provide compelling evidence for the role of accessibility experiences in frequency judgments.

\section{The Diagnosticity of Accessibility Experiences: Frequency Judgments}

To test these predictions, Wänke, Schwarz, and Bless (1995) conducted a modified replication of Tversky and Kahneman's (1973, Experiment 3) letter experiment. In the control condition, participants received 
a blank sheet of paper and were asked to first write down 10 words that have $t$ as the third letter and subsequently 10 words that begin with the letter $t$. Following this listing task, they rated the extent to which words beginning with a $t$ are more or less frequent than words that have $t$ as the third letter. As in Tversky and Kahneman's (1973) study, participants estimated that words that begin with a $t$ are much more frequent than words having a $t$ in the third position. To isolate the role of experienced ease, the diagnosticity of the experience was manipulated in two experimental conditions. Specifically, participants had to record 10 words that begin with a $t$ on a sheet of paper that was imprinted with pale but visible rows of $t \mathrm{~s}$. Some participants were told that this background would make it easy to recall $t$ words (the facilitating condition), whereas others were told that this background would interfere with the recall task (the inhibiting condition). As expected, participants who could attribute the experienced ease of recall to the impact of their work sheet assumed that there are fewer $t$ words than did participants in the control condition. Conversely, participants who expected their work sheet to interfere with recall, but found recall easy nevertheless, estimated that there are more $t$ words than did participants in the control condition. In combination, these discounting and augmentation effects indicate that participants did indeed base their frequency estimates on the implications of their subjective experience of ease of recall rather than on the number of words they could bring to mind.

\section{The Diagnosticity of Accessibility Experiences: Judgments of One's Own Memory}

In a similar vein, Winkielman, Schwarz, and Belli (1998; see also Belli, Winkielman, Read, Schwarz, \& Lynn, in press) observed that judgments of how much one can remember about one's own childhood are based on the ease with which childhood memories can be brought to mind. Depending on conditions, participants had to recall either 4 (an easy task) or 12 (a difficult task) childhood events and were subsequently asked, "Are there large parts of your childhood after age 5 which you can't remember?" (yes, unsure, and no; a question taken from Ross, 1989). Whereas $46 \%$ of the participants who had to recall 12 memories inferred that they could not remember large parts of their childhood, only $19 \%$ of the participants who had to recall 4 events did so. Thus, the former participants inferred poorer memory than the latter, despite the fact that they had just recalled three times as many events. Presumably, they based their judgment on the difficulty they encountered rather than on the number of events recalled. Supporting this interpretation, informing participants in another condition that recalling 12 childhood events is a difficult task reduced reports of poor childhood memory to $27 \%$, an estimate that does not reliably differ from the four-events condition. Under this condition, they (correctly) attributed the experienced difficulty to the nature of the task rather than to the poor quality of their childhood memory, thus eliminating the otherwise observed impact. ${ }^{1}$

Similar (mis)attribution effects have been obtained in other domains, to be addressed subsequently (Schwarz, Bless, et al., 1991, Experiment 3). In combination, the Wänke et al. (1995) and Winkielman et al. (1998) findings demonstrate that accessibility experiences serve as a source of information in their own right, much as has been observed for other types of experiential information (see Clore, 1992; Schwarz \& Clore, 1996; Strack, 1992).

\section{Facial Feedback as an Indicator of Recall Difficulty}

If accessibility experiences constitute a distinct source of information, any variable that leads people to experience a given recall task as easy or difficult should have the same effect as actual ease or difficulty of recall, even when the experience is induced by an unrelated variable. A study by Stepper and Strack (1993, Experiment 2) supported this implication. These authors asked all participants to recall six examples of assertive or unassertive behavior, thus holding actual recall demands constant. To manipulate the subjective recall experiences, they induced participants to contract either their corrugator muscle or their zygomaticus muscle during the recall task. Contraction of the corrugator muscle produces a furrowed brow, an expression commonly associated with a feeling of effort. Contraction of the zygomaticus muscle produces a light smile, an expression commonly associated with a feeling of ease.

Reflecting the impact of this proprioceptive feedback, participants who recalled six examples of assertive behavior while adopting a light smile judged themselves as more assertive than participants who adopted a furrowed brow. Conversely, participants who recalled six examples of unassertive behavior while adopting a light smile judged themselves as less assertive than participants who adopted a furrowed brow. Apparently, the experience of difficulty conveyed by a furrowed brow led participants to conclude that they could not be that assertive (or unassertive) if it was so difficult to

\footnotetext{
'Note also that these findings suggest that attempts to recall large amounts of childhood information are likely to result in inferences of poor childhood memory, even when recall is successful. This observation bears in important ways on procedures designed to recover childhood memories, which figure prominently in current discussions of childhood amnesia as a function of childhood abuse (see Belli et al., in press, for a discussion).
} 
bring assertive (or unassertive, respectively) behaviors to mind.

\section{Conclusions}

In combination, these studies demonstrate that subjective accessibility experiences constitute a source of information that is distinct from the content that has been brought to mind. In the previously mentioned studies, the actual recall task and the amount of information brought to mind was held constant. Nevertheless, participants arrived at different judgments depending on the subjective recall experience conveyed by proprioceptive feedback (Stepper \& Strack, 1993). Moreover, the impact of experienced ease or difficulty of recall depended on its perceived diagnosticity (Wänke et al., 1995; Winkielman et al., 1998). Finally, where accessible content and accessibility experiences suggested different conclusions, participants relied on the experiential information and inferred poorer memory after recalling 12 rather than 4 childhood events, unless they were led to attribute the experienced difficulty of recall to the nature of the task (Winkielman et al., 1998).

Based on these findings, we may conclude that the availability heuristic (Tversky \& Kahneman, 1973) does indeed describe a metacognitive judgment strategy that is based on a monitoring of one's own recall experiences, with close attention to their apparent diagnosticity. Accordingly, judgments of frequency, likelihood, and typicality are often based on the ease with which relevant material can be brought to mind, although this is not the only strategy available to individuals.

\section{Differential Implications of Accessible Content and Accessibility Experiences}

As noted previously, the conditions under which a recall task is experienced as easy are often conditions under which we are also likely to recall a large number of instances. Under these conditions, reliance on accessible content leads to the same conclusions as reliance on accessibility experiences. It is possible, however, to create conditions under which reliance on these different sources of information leads to different judgments. Suppose that some individuals are asked to recall 6 examples of situations in which they behaved assertively, whereas others are asked to recall 12 examples. Suppose further that recalling 6 examples is experienced as easy, whereas recalling 12 examples is experienced as difficult. In this case, a judgment strategy that is based on recalled content would lead individuals to infer higher assertiveness when the recall task brought 12 rather than 6 examples to mind, as shown in the top panel of Figure 1. In contrast, a strategy based on experienced ease or difficulty of recall would reverse this pattern, as shown in the bottom panel of Figure 1: Finding it difficult to recall 12 examples of assertive behaviors, individuals may conclude that they cannot be that assertive after all-or else bringing 12 examples to mind would not be that difficult. Several studies bear on this differential impact of accessible content and accessibility experiences, which was also reflected in the Winkielman et al. (1998) findings discussed previously.

\section{Accessible Content Versus Accessibility Experiences}

In an initial test of this possibility, Schwarz, Bless, et al. (1991, Experiment 1) asked participants to report either 6 or 12 situations in which they behaved either assertively or unassertively. Although all participants could complete this task, pretests had shown that recalling 6 examples was experienced as easy, whereas recalling 12 examples was experienced as difficult. Following their reports, participants had to evaluate their own assertiveness. Table 1 shows the results.

As expected, participants reported higher assertiveness after recalling 6 examples of assertive behaviors than after recalling 6 examples of unassertive behaviors. However, this difference did not increase as participants had to recall more examples. To the contrary, participants who had to recall assertive behaviors reported lower assertiveness after recalling 12 rather than 6 examples. Similarly, participants who had to recall unassertive behaviors reported higher assertiveness after recalling 12 rather than 6 examples. In fact, they reported higher assertiveness after recalling 12 unassertive rather than 12 assertive behaviors, in contrast to what one would expect on the basis of recalled content. Apparently, the experience that it was difficult to bring 12 examples to mind suggested to them that they could not be that assertive (or unassertive) after all, resulting

Table 1. Self-Reports of Assertiveness as a Function of Valence and Number of Recalled Behaviors

Type of Behavior

\begin{tabular}{lcc}
\cline { 2 - 3 } $\begin{array}{l}\text { Number of } \\
\text { Recalled Examples }\end{array}$ & Assertive & Unassertive \\
\hline Six & 6.3 & 5.2 \\
Twelve & 5.2 & 6.2 \\
\hline
\end{tabular}

Note: $N$ is 9 or 10 per condition. Mean score of three questions is given; possible range is 1 to 10 , with higher values reflecting higher assertiveness. From "Ease of retrieval as information: Another look at the availability heuristic," by N. Schwarz, H. Bless, et al., 1991, Journal of Personality and Social Psychology, 61, p. 197. Copyright (C) 1991 by the American Psychological Association. Adapted with permission. 


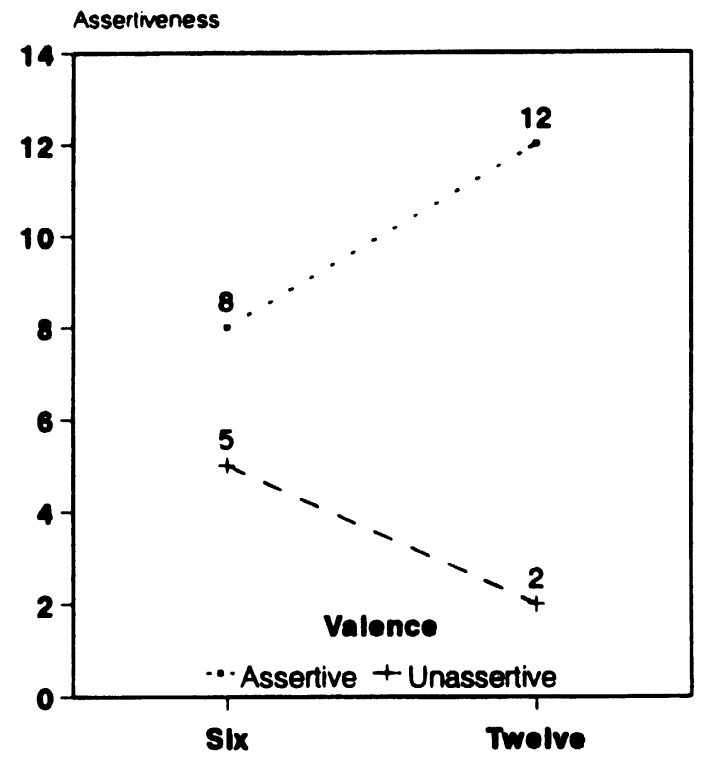

Number of Recalled Instances

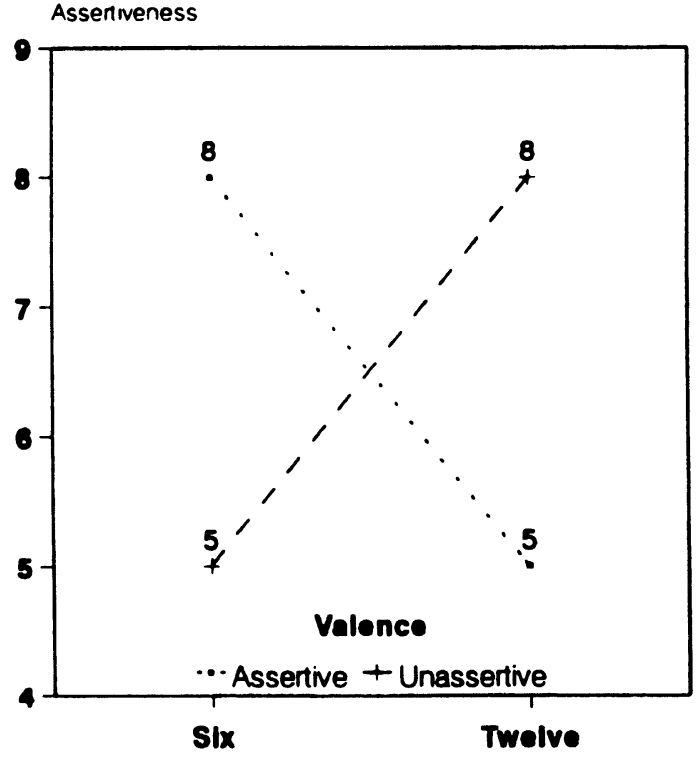

Number of Recalled Instances

Figure 1. Predicted judgments of assertiveness. Top panel: Judgments formed on the basis of content of recall. Bottom panel: Judgments formed on the basis of experienced ease of recall. 
in inferences opposite to the implications of recalled content.

However, a possible alternative explanation deserves attention. Although all participants who were asked to do so did in fact report 12 examples, it is conceivable that the quality of their examples changed over the course of the recall task: They may have been able to recall some examples of clearly assertive behavior early on, but as the requested number increased, they had to include less and less convincing examples of assertiveness. If so, these less convincing examples, reported toward the end of the list, may have been more accessible later on than the examples reported earlier. Hence, if participants based their judgments on the last few examples generated, one would obtain the same pattern of results. Schwarz, Bless, et al. (1991, Experiment 1 ) tested this possibility by analyzing the examples that participants reported. This content analysis provided no evidence that the extremity of the examples decreased toward the end. If anything, the last 2 examples reported were somewhat more extreme than the first 2 examples reported. Thus, this alternative explanation can be discarded.

\section{Undermining the Diagnosticity of Accessibility Experiences}

To provide more direct evidence for the assumed role of accessibility experiences, Schwarz, Bless, et al. (1991, Experiment 3) manipulated the perceived informational value of the experienced ease or difficulty of recall. To accomplish this, they had participants listen to New Age music played at half-speed while they worked on the recall task. Participants were told that this music would facilitate the recall of a certain kind of autobiographical memories, namely, either memories of situations in which one behaved assertively and felt at ease or situations in which one behaved unassertively and felt insecure. This manipulation renders participants' accessibility experiences uninformative under conditions where these experiences could be due to the alleged impact of the music. For example, finding it easy to bring 6 examples of assertive behavior to mind is not very informative with regard to one's own assertiveness when the experienced ease of recall may actually be due to the music. Similarly, finding it difficult to recall 12 examples of assertive behavior is also not informative when the music allegedly facilitates the recall of the opposite behavior, which may interfere with one's recall efforts. On the other hand, participants' accessibility experiences are rendered particularly diagnostic when they contradict the alleged side effects of the music. Thus, when the music is said to make the recall of assertive behaviors easy, finding it difficult to recall 12 assertive behaviors should provide food for thought. As in the Wänke et al. (1995) study reviewed previously, participants should rely on their accessibility experiences only when their informational value is not called into question. If these experiences may be due to the alleged impact of the music, however, participants may disregard their subjective experiences and may rely on recalled content instead.

The findings supported these predictions. When the informational value of participants' experienced ease or difficulty of recall was not called into question, the previously obtained results replicated. Thus, participants evaluated themselves as less assertive after recalling 12 rather than 6 examples of assertive behavior and as more assertive after recalling 12 rather than 6 examples of unassertive behavior. Not so, however, when the informational value of their accessibility experiences was called into question. In this case, participants reported higher assertiveness after recalling 12 rather than 6 examples of assertive behavior and lower assertiveness after recalling 12 rather than 6 examples of unassertive behavior. In other words, their judgments reflected the content of the examples they recalled, and the more so, the more examples were brought to mind.

\section{Perceived Expertise and the Informational Value of Recall Experiences}

In the preceding studies, the informational value of recall experiences was manipulated by drawing participants' attention to an external source that allegedly facilitated or inhibited recall. The same logic, however, applies to an individual difference variable, namely, one's perceived expertise in the respective content domain. Suppose you are asked to list 12 famous Spanish matadors and you find this task difficult. Chances are that you would not conclude that there are not many famous Spanish matadors-instead, you would blame your own lack of expertise for the experienced difficulty, thus undermining its informational value. As this example illustrates, individuals may rely on recall experiences only when they consider themselves at least moderately knowledgeable in the relevant content domain. Experimental data support this conclusion.

For example, Biller, Bless, and Schwarz (1992) had participants recall either three (easy) or nine (difficult) examples of chronic diseases and subsequently asked them to estimate the percentage of the population who suffer from chronic diseases. As expected, they estimated the prevalence of chronic diseases to be higher after recalling three $(M=38.3 \%)$ rather than nine $(M=$ $25.2 \%$ ) examples, indicating that they based their judgments on their accessibility experiences. To test the role of perceived expertise, other participants were first asked to indicate how much they knew about chronic diseases, thus drawing their attention to their general lack of knowledge in this domain. In this case, participants estimated the prevalence of chronic diseases to be 
lower after recalling three $(M=23.1 \%)$ rather than nine $(M=33.0 \%)$ examples, indicating that they based their judgments on the number of examples recalled.

These findings suggest that people will rely on their subjective recall experiences only when they consider themselves knowledgeable but will turn to recalled content when they do not (see also Schwarz \& Schuman, 1997). Extending this line of research, Vaughn (1997) explored the role of a particular kind of expertise, namely, schematicity with regard to a personality trait (Markus, 1977). Specifically, Markus asked assertiveness schematics (who are considered experts on this trait) and aschematics (nonexperts) to recall either three or eight examples of their own assertive behavior. As expected, assertiveness schematics based their self-assessments on their subjective recall experience and reported higher assertiveness after recalling three (easy) rather than eight (difficult) examples. Conversely, assertiveness aschematics discounted their subjective accessibility experience and based their self-assessments on recalled information, reporting higher assertiveness after recalling eight rather than three examples.

In combination, these studies indicate that perceived knowledgeability is a crucial prerequisite for reliance on experienced ease or difficulty of recall as a source of information. When people are aware, or are made aware, of a lack of knowledge in the respective domain, the diagnostic value of accessibility experiences is called into question, much as is the case when their attention is drawn to external factors likely to influence their recall experience.

\section{Depriving Judges of Experiential Information}

Similar conclusions are suggested by a study in which judges did or did not have access to experiential information. Specifically, Wänke, Bless, and Biller (1996) asked participants to generate either three or seven reasons for using or not using public transportation. Replicating previous findings, participants reported more favorable attitudes toward public transportation after they generated three (easy) rather than seven (difficult) proarguments or seven (difficult) rather than three (easy) antiarguments (see Haddock, Rothman \& Schwarz, 1996). Thus, participants who had access to relevant content as well as accessibility experiences relied on their experiences in arriving at a judgment. A group of yoked participants, however, were not asked to generate reasons but read the reasons generated by other participants, thus depriving them of the experiential information available to the participants who generated the arguments. As may be expected, these participants drew on the content of the arguments as the only source of information available to them and reported more favorable attitudes toward public transpor- tation after reading seven rather than three proarguments and more negative attitudes after reading seven rather than three antiarguments.

As this example illustrates, the recipients of a communicator's arguments may arrive at the opposite conclusions as the communicator himself or herself. Whereas the recipient can only draw on the implications of the communicated arguments, the communicator may qualify these implications by considering how easy or difficult it was to generate the arguments in the first place.

\section{Conclusions}

The reviewed studies demonstrate that recall tasks render two distinct sources of information available: the recalled content and the ease or difficulty with which it can be brought to mind. Depending on which source judges draw on, they may arrive at opposite conclusions. Hence, we cannot predict their judgments on the basis of recalled content alone but need to take into account whether the content was easy or difficult to bring to mind and whether or not this subjective experience is deemed diagnostic. When the diagnosticity of accessibility experiences is called into question, either due to external factors or a perceived lack of knowledge, or when no experiential information is available, judges turn to recalled content as the more informative source of information. In many cases, however, both sources of information may seem similarly diagnostic. What determines which source of information will be preferred under these conditions? In the next section I address this issue.

\section{Accessibility Experiences Versus Accessible Content: The Influence of Processing Motivation}

Consistent with the notion of an availability heuristic, we may consider reliance on ease of recall a heuristic strategy, suggesting that variables known to determine the degree of heuristic processing should influence the extent to which individuals rely on this source of information. As a large body of research in social cognition demonstrated, individuals' judgment strategies depend, ceteris paribus, on the motivation they bring to the task. The more self-relevant and involving the task is, the more likely they are to adopt a systematic processing strategy, paying attention to the specific implications of the information that comes to mind. In contrast, heuristic processing strategies are preferred for less relevant and less involving tasks (for variations on this theme, see Brewer, 1988; Chaiken, Liberman, \& Eagly, 1989; Eagly \& Chaiken, 1993; Fiske \& Neuberg, 1990; Petty \& Cacioppo, 1986). If 
so, the self-relevance of the material addressed in the recall task may determine whether individuals rely on accessible content or accessibility experiences in forming a judgment.

\section{Assessing One's Vulnerability to Heart Disease}

To test this possibility, Rothman and Schwarz (in press) asked male undergraduates to list either three or eight behaviors that they personally engage in that may either increase or decrease their risk of heart disease. Pretests indicated that listing three behaviors was experienced as easy, whereas listing eight was experienced as difficult. The personal relevance of the task was assessed via a background characteristic, namely, whether or not participants had a family history of heart disease. Supposedly, assessing their own risk of heart disease is a more relevant task for men whose family history puts them at higher risk than for men without a family history of heart disease. Hence, participants with a family history of heart disease should be likely to adopt a systematic processing strategy, paying attention to the specific behaviors brought to mind by the recall task. In contrast, participants without a family history may rely on a heuristic strategy, drawing on the subjective experience of ease or difficulty of recall.

As shown in Table 2, the results supported these predictions. The top half shows participants' self-re-

Table 2. Vulnerability to Heart Disease as a Function of Type and Number of Recalled Behaviors and Family History

\begin{tabular}{llc}
\hline & \multicolumn{2}{c}{ Type of Behavior } \\
\cline { 2 - 3 } Judgment & Risk-Increasing & Risk-Decreasing \\
\hline Vulnerability Judgments & & \\
With Family History & & 5.8 \\
$\quad$ 3 Examples & 4.6 & 3.8 \\
$\quad$ 8 Examples & 5.4 & 3.1 \\
Without Family History & & 4.3 \\
3 Examples & 3.9 & \\
8 Examples & 3.2 & \\
& & \\
Need for Behavior Change & & 5.2 \\
With Family History & 3.6 & 4.7 \\
3 Examples & 6.3 & 3.0 \\
8 Examples & & 5.6 \\
Without Family History & 3.4 & \\
3 Examples & 2.8 & \\
8 Examples & & \\
\hline
\end{tabular}

Note: $N$ is 8 to 12 per condition. Judgments of vulnerability and the need to change current behavior were made on 9-point scales, with higher values indicating greater vulnerability and need to change, respectively. Adapted from "Constructing perceptions of vulnerability: Personal relevance and the use of experimental information in health judgments," by A. J. Rothman and N. Schwarz, in press, Personality and Social Psychology Bulletin. Copyright (c) 1998 by Sage Publications. Reprinted by Permission of Sage Publications, Inc. ported vulnerability to heart disease. As expected, men with a family history of heart disease drew on the relevant behavioral information they recalled. Hence, they reported higher vulnerability after recalling eight rather than three risk-increasing behaviors and lower vulnerability after recalling eight rather than three riskdecreasing behaviors. In contrast, men without a family history of heart disease drew on their accessibility experiences, resulting in the opposite pattern. They reported lower vulnerability after recalling eight (difficult) rather than three (easy) risk-increasing behaviors and higher vulnerability after recalling eight rather than three risk-decreasing behaviors.

In addition, participants' perceived need for behavior change paralleled their vulnerability judgments, as shown in the bottom half of Table 2 . Note that participants with a family history of heart disease reported the highest need for behavior change after recalling eight risk-increasing behaviors, whereas participants without a family history reported the lowest need for behavior change under this condition, again illustrating a reversal in the judgmental outcome.

\section{Assessing One's Vulnerability to Sexual Assault}

Supporting the robustness of these findings, Grayson and Schwarz (1997) observed a parallel pattern when women were asked to assess their vulnerability to sexual assault. In their study, women had to recall four or eight behaviors they personally engaged in that may either increase or decrease their risk of sexual assault. Some of these women assumed that sexual assault only happens to women who "ask for it," thus reducing the personal relevance of the recall task. These women relied on ease of recall and inferred higher vulnerability after recalling four rather than eight riskincreasing behaviors or eight rather than four risk-decreasing behaviors. Other women assumed that sexual assault may happen to any woman, thus increasing the personal relevance of the recall task. These women relied on content of recall and inferred lower vulnerability after recalling four rather than eight risk-increasing behaviors or eight rather than four risk-decreasing behaviors. Thus, women's beliefs about sexual assault determined the judgment strategy used, as did a family history of heart disease in Rothman and Schwarz's (in press) study.

\section{Conclusions}

In combination, these findings again illustrate that the same recall task renders two distinct sources of information available: accessible content and accessibility experiences. Depending on which source indi- 
viduals draw on, they arrive at opposite conclusions. In fact, analyses of the Rothman and Schwarz (in press) data, shown in Table 2, did not reveal a main effect of the content of the recall task, nor did analyses of the Grayson and Schwarz data. In neither study could one predict the impact of thinking about risk-increasing or risk-decreasing behaviors without knowing if individuals found it easy or difficult to bring the respective behaviors to mind and which judgmental strategy they were likely to use.

Note also that the observed impact of personal involvement on individuals' processing strategy contradicts the common assumption that reliance on the availability heuristic is independent of judges' motivation. In several studies, researchers offered participants incentives for arriving at the correct answer, yet such incentives rarely attenuated reliance on the availability heuristic (see Nisbett \& Ross, 1980; Payne, Bettman, \& Johnson, 1993). Unfortunately, these studies could not observe a change in processing strategy, even if it occurred. To see why, suppose that one presented participants with a list of the names of 19 famous women and 20 nonfamous men (Tversky \& Kahneman, 1973). Suppose further that some participants are offered an incentive to arrive at the correct estimate of the proportion of female names on the list, whereas others are not. Without an incentive, individuals may rely on a heuristic strategy, drawing on experienced ease of recall. This would lead them to conclude that there were more female than male names on the list. With a successful incentive, however, they may be motivated to invest more effort. If so, they may recall as many names as they can and may count the number of female names in the recalled sample. Unfortunately, this systematic strategy would lead them to the same conclusion, because the famous female names would be overrepresented in the recalled sample.

As this example illustrates, we can only distinguish between heuristic and systematic strategies when we introduce conditions under which both strategies lead to different outcomes. When this is done, we are likely to observe the expected impact of processing motivation, as the previously mentioned findings illustrate.

\section{Anticipated Accessibility Experiences: Is It Enough to Imagine the Task?}

All of the research examples reviewed so far elicited accessibility experiences by having participants engage in an easy or a difficult recall task. However, Tversky and Kahneman (1973) suggested that "it is not necessary to perform the actual operations of retrieval.... It suffices to assess the ease with which these operations could be performed" (p. 208, italics added). To address this possibility, Wänke, Bohner, and Jurkowitsch (in press) exposed participants to different advertisements for luxury cars. Depending on conditions, the ad read, "There are many reasons to choose a BMW. Can you name one (ten, respectively)?" As predicted, participants reported more favorable attitudes toward BMW cars when the ad prompted them to name only 1 reason rather than to name 10 reasons. This difference was obtained even though only $49 \%$ of the participants in the 1 -reason condition and $30 \%$ of the participants in the 10 -reasons condition reported that they attempted to generate any reasons. Moreover, the obtained patterns did not differ as a function of whether or not participants actually attempted to generate any reasons, suggesting that anticipated accessibility experiences are just as informative as actually experienced ones.

\section{Theoretical Implications}

The reviewed research highlights the role of accessible content and accessibility experiences in judgment and circumscribes the conditions under which individuals are likely to make use of these distinct sources of information. In this final section I summarize the implications for the operation of the accessibility heuristic and the emergence of knowledge accessibility effects in social judgment and I identify avenues for future research.

\section{Availability Heuristic}

Judgments of frequency and likelihood can be based on either recalled content or on the ease or difficulty with which this content can be brought to mind. In most situations, these two sources of information are naturally confounded, a problem that rendered many of the classic tests of the availability heuristic nondiagnostic. When this confound is disentangled, the available evidence supports the original formulation of the availability heuristic as a metacognitive judgment strategy: Individuals estimate the frequency of an event, the likelihood of its occurrence, and its typicality "by the ease with which instances or associations come to mind" (Tversky \& Kahneman, 1973, p. 208). However, this strategy is not always employed.

First, individuals only rely on accessibility experiences as a source of information when their informational value is not called into question. When they attribute their experiences to an external influence (e.g., Rothman \& Hardin, 1997; Schwarz, Bless, et al., 1991; Wänke et al., 1995) or are aware that they may not be knowledgeable about the content domain (e.g., Biller et al., 1992; Vaughn, 1997), the otherwise observed impact of accessibility experiences is eliminated. This parallels the use of other sources of experiential information, such as moods, emotions, or bodily states (see Schwarz \& Clore, 1996).

Second, when accessibility experiences are considered nondiagnostic, individuals turn to the content of 
recall as an alternate source of information (e.g., Schwarz, Bless, et al., 1991). Under unconstrained conditions, reliance on recalled content is likely to lead to the same outcome as reliance on ease of recall becanse recall is experienced as easy when a large number of examples can be brought to mind. When people are induced to recall a few versus many examples, however, these two sources of information have opposite implications: Whereas the experienced ease (or difficulty) suggests that there are many (few) examples, the actual examples recalled lead to the opposite conclusion.

Finally, individuals are likely to rely on accessibility experiences when the judgment task is of low personal relevance but draw on recalled content when the task is of high personal relevance (e.g., Grayson \& Schwarz, 1997; Rothman \& Schwarz, in press). This influence of processing motivation is consistent with dual-process models of judgment (e.g., Brewer, 1988; Chaiken et al., 1989; Fiske \& Neuberg, 1990; Petty \& Cacioppo, 1986). However, it could not be observed in previous studies, which confounded ease and content of recall. Accordingly, incentives may very well attenuate reliance on the availability heuristic, in contrast to previous conclusions (e.g., Nisbett \& Ross, 1980). This possibility awaits empirical testing.

\section{Knowledge Accessibility Effects}

In addition, the reviewed research bears on knowledge accessibility effects in social judgment (see Higgins, 1996). Specifically, it suggests an intricate interplay of accessible content and accessibility experiences that is not captured by common assumptions in social cognition research.

First, one of the truisms of social cognition research holds that judgments of a known target are based on the declarative information that is most accessible in memory at the time of judgment. Yet, the reviewed findings indicate that this is only the case when the respective information is easy to bring to mind. When recall is experienced as difficult, judges arrive at conclusions that contradict the implications of what comes to mind. They may infer, for example, that they are less assertive after recalling 12 examples of assertive behavior than after recalling 12 examples of unassertive behavior (Schwarz, Bless, et al., 1991). Findings of this type indicate that the implications of accessible content are qualified by the subjective experiences that accompany its recall. Hence, judgments reflect the semantic implications of accessible content when this content is easy to bring to mind but reflect the opposite implications when the same content is difficult to bring to mind.

Second, although the data bearing directly on this conclusion are limited to memory-based judgments of known targets, such as the self, similar qualifications may apply to the interpretation of newly acquired information. In general, it is assumed that new information is interpreted in terms of the applicable concept that is most accessible at the time of encoding, leading participants in the Higgins et al. (1977) study to conclude, for example, that Donald is either stubborn or persistent, depending on which concept was primed. Again, it is conceivable that the ease with which the primed concept comes to mind contributes to the impression that it provides a good description of the target. In fact, when participants are aware that the concept may come to mind due to the potential influence of the priming episode, they are unlikely to apply it in characterizing the target (e.g., Lombardi, Higgins, \& Bargh, 1987; Martin, 1986; Strack, Schwarz, Bless, Kübler, \& Wänke, 1993). Although this observation parallels the finding that accessibility experiences are not used when alleged external influences undermine their informational value (e.g., Schwarz, Bless, et al., 1991), awareness of the priming episode may affect judgments for a number of different reasons (see Martin \& Achee, 1992; Strack, 1992). Accordingly, more targeted research will be needed to isolate the role of accessibility experiences in the interpretation of new information.

Finally, the reviewed findings indicate that the use of accessible content or accessibility experiences depends on individuals' processing strategy, which is itself a function of their motivation and ability at the time of judgment (e.g., Chaiken et al., 1989; Petty \& Cacioppo, 1986). As a result, knowing what comes to mind, or knowing how easily it comes to mind, is not sufficient to predict the judgmental outcome. Instead, we also need to take individuals' processing motivation into account: Individuals who rely on a systematic processing strategy are likely to draw on accessible content, whereas individuals who rely on a heuristic processing strategy are likely to draw on subjective accessibility experiences, resulting in opposite conclusions despite having engaged in the same task (Grayson \& Schwarz, 1997; Rothman \& Schwarz, in press).

As these complexities illustrate, knowledge accessibility effects are not well captured by the popular assumption that judgments depend on what happens to come to mind at the time. Instead, we need to consider the accessible content as well as the subjective experiences that accompany it and need to pay attention to individuals' processing motivation, which determines which of these distinct sources of information they are likely to draw on.

\section{References}

Belli, R. F., Winkielman, P., Read, J. D., Schwarz, N., \& Lynn, S. J. (in press). Recalling more childhood events leads to judgments of poorer memory: Implications for the recovered/false memory debate. Psychonomic Bulletin \& Review.

Benjamin, A. S., \& Bjork, R. A. (1996). Retrieval fluency as a metacognitive index. In L. M. Reder (Ed.), Implicit memory and metacognition (pp. 309-338). Mahwah, NJ: Lawrence Erlbaum Associates, Inc. 
Biller, B., Bless, H., \& Schwarz, N. (1992, April). Die Leichtigkeit der Erinnerung als Information in der Urteilsbildung: Der Einflu $\beta$ der Fragenreihenfolge [Ease of recall as information: The impact of question order]. Tagung experimentell arbeitender Psychologen, Osnabrück, Germany.

Bodenhausen, G. V., \& Wyer, R. S. (1987). Social cognition and social reality: Information acquisition and use in the laboratory and the real world. In H. J. Hippler, N. Schwarz, \& S. Sudman (Eds.), Social information processing and survey methodology (pp. 6-41). New York: Springer-Verlag.

Brewer, M. B. (1988). A dual process model of impression formation. In T. K. Srull \& R. S. Wyer, Jr. (Eds.), Advances in Social Cognition, (Vol. 1, pp. 1-36). Hillsdale, NJ: Lawrence Erlbaum Associates, Inc.

Chaiken, S., Liberman, A., \& Eagly, A. H. (1989). Heuristic and systematic p cessing within and beyond the persuasion context. In J. S. Uleman \& J. A. Bargh (Eds.), Unintended thought (pp. 215-252). New York: Guilford.

Clore, G. L. (1992). Cognitive phenomenology: Feelings and the construction of judgment. In L. L. Martin \& A. Tesser (Eds.), The construction of social judgments (pp. 133-163). Hillsdale, NJ: Lawrence Erlbaum Associates, Inc

Eagly, A., \& Chaiken, S. (1993). The psychology of attitudes. New York: Harcourt Brace Jovanovich.

Fiske, S. T., \& Neuberg, S. L. (1990). A continuum of impression formation, from category-based to individuating processes: Influences of information and motivation on attention and interpretation. In M. P. Zanna (Ed.), Advances in experimental social psychology (Vol. 23, pp. 1-74). San Diego, CA: Academic.

Gabrielcik, A., \& Fazio, R. H. (1984). Priming and frequency estimation: A strict test of the availability heuristic. Personality and Social Psychology Bulletin, 10, 85-89.

Grayson, C. E., \& Schwarz, N. (1997). Beliefs influence information processing strategies: Declarative and experiential information in risk assessment. Unpublished manuscript.

Haddock, G., Rothman, A., \& Schwarz, N. (1996). Are (some) reports of attitude strength context dependent? Canadian Journal of Behavioral Science, 24, 313-317.

Higgins, E. T. (1989). Knowledge accessibility and activation: Subjectivity and suffering from unconscious sources. In J. S. Uleman \& J. A. Bargh (Eds.), Unintended thought (pp.75-123). New York: Guilford.

Higgins, E. T. (1996). Knowledge: Accessibility, applicability, and salience. In E. T. Higgins \& A. Kruglanski (Eds.), Social psychology: Handbook of basic principles (pp. 133-168). New York: Guilford.

Higgins, E. T., Rholes, W. S., \& Jones, C. R. (1977). Category accessibility and impression formation. Journal of Experimental Social Psychology, 13, 141-154.

Jacoby, L. L., \& Kelley, C. M. (1987). Unconscious influences of memory for a prior event. Personality and Social Psychology Bulletin, 13, 314-336.

Jacoby, L. L., \& Whitehouse, K. (1989). An illusion of memory: False recognition influenced by unconscious perception. Journal of Experimental Psychology: General, 118, 126-135.

Kelley, C. M., \& Jacoby, L. L. (1996). Memory attributions: Remembering, knowing, and feeling of knowing. In L. M. Reder (Ed.), Implicit memory and metacognition (pp. 287-308). Mahwah, NJ: Lawrence Erlbaum Associates, Inc

Kelley, C. M., \& Lindsay, D. S. (1993). Remembering mistaken for knowing: Ease of retrieval as a basis for confidence in answers to general knowledge questions. Journal of Memory and Language, 32, 1-24.

Kelley, H. H. (1972). Causal schemata and the attribution process. Morristown, NJ: General Learning Press.

Koriat, A. (1993). How do we know that we know? The accessibility model of the feeling of knowing. Psychological Review, 100, 609-639.
Lombardi, W. J., Higgins, E. T., \& Bargh, J. A. (1987). The role of consciousness in priming effects on categorization: Assimilation versus contrast as a function of awareness of the priming task. Personality and Social Psychology Bulletin, 13, 411-429.

Markus, H. R. (1977). Self-schemata and processing of information about the self. Journal of Personality and Social Psychology, $35,63-78$.

Martin, L. L. (1986). Set/reset: Use and disuse of concepts in impression formation. Journal of Personality and Social Psychology, 51, 493-504.

Martin, L. L., \& Achee, J. W. (1992). Beyond accessibility: The role of processing objectives in judgment. In L. L. Martin \& A. Tesser (Eds.), The construction of social judgment (pp. 195-216). Hillsdale, NJ: Lawrence Erlbaum Associates, Inc.

Martin, L. L., \& Clark, L. F. (1990). Social cognition: Exploring the mental processes involved in human social interaction. In M.W. Eysenck (Ed.), Cognitive psychology: An international review (pp. 265-310). Chichester, England: Wiley.

Medin, D. L., \& Ross, B. H. (1997). Cognitive psychology (2nd ed.). Fort Worth, TX: Harcourt Brace.

Nisbett, R. E., \& Ross, L. (1980). Human inference: Strategies and shortcomings of social judgment. Englewood Cliffs, NJ: Prentice Hall.

Payne, J. W., Bettman, J. R., \& Johnson, E. J. (1993). The adaptive decision maker. New York: Cambridge University Press.

Petty, R. E., \& Cacioppo, J. T. (1986). The elaboration likelihood model of persuasion. In L. Berkowitz (Ed.), Advances in experimental social psychology (Vol. 19, pp. 123-205). New York: Academic.

Ross, C. A. (1989). Multiple personality disorder: Diagnosis, clinical features, and treatment. New York: Wiley.

Rothman, A. J., \& Hardin, C. (1997). Differential use of the availability heuristic in social judgment. Personality and Social Psychology Bulletin, 23, 123-138.

Rothman, A. J., \& Schwarz, N. (in press). Constructing perceptions of vulnerability: Personal relevance and the use of experiential information in health judgments. Personality and Social Psychology Bulletin.

Schwarz, N. (1995). Social cognition: Information accessibility and use in social judgment. In E. E. Smith \& D. N. Osherson (Eds.), Thinking. An invitation to cognitive science (Vol. 3, 2nd ed., pp. 345-376). Cambridge, MA: MIT Press.

Schwarz, N., \& Bless, H. (1992). Constructing reality and its alternatives: Assimilation and contrast effects in social judgment. In L. L. Martin \& A. Tesser (Eds.), The construction of social judgment (pp. 217-245). Hillsdale, NJ: Lawrence Erlbaum Associates, Inc.

Schwarz, N., Bless, H., Strack, F., Klumpp, G., Rittenauer-Schatka, H., \& Simons, A. (1991). Ease of retrieval as information: Another look at the availability heuristic. Journal of Personality and Social Psychology, 61, 195-202.

Schwarz, N., \& Clore, G. L. (1983). Mood, misattribution, and judgments of well-being: Informative and directive functions of affective states. Journal of Personality and Social Psychology, $45,513-523$.

Schwarz, N., \& Clore, G. L. (1996). Feelings and phenomenal experiences. In E. T. Higgins \& A. Kruglanski (Eds.), Social psychology: A handbook of basic principles (pp. 433-465). New York: Guilford.

Schwarz, N., \& Schuman, H. (1997). Political knowledge, attribution, and inferred political interest: The operation of buffer items. International Journal of Public Opinion Research, 9, 191-195.

Schwarz, N., Strack, F., \& Mai, H. P. (1991). Assimilation and contrast effects in part-whole question sequences: A conversational logic analysis. Public Opinion Quarterly, 55, 3-23.

Sherman, S. J., \& Corty, E. (1984). Cognitive heuristics. In R. S. Wyer \& T. K. Srull (Eds.), Handbook of social cognition (Vol. 1, pp. 189-286). Hillsdale, NJ: Lawrence Erlbaum Associates, Inc. 
Stepper, S., \& Strack, F. (1993). Proprioceptive determinants of emotional and nonemotional feelings. Journal of Personality and Social Psychology, 64, 211-220.

Strack, F. (1985). Urteilsheuristiken [Judgmental heuristics]. In D. Frey \& M. Irle (Eds.), Theorien der Sozialpsychologie (Vol: 3, pp. 239-267). Bern, Switzerland: Huber.

Strack, F. (1992). The different routes to social judgment: Experiential versus informational strategies. In L. L. Martin \& A. Tesser (Eds.), The construction of social judgments (pp. 249-276). Hillsdale, NJ: Lawrence Erlbaum Associates, Inc.

Strack, F., Schwarz, N., Bless, H., Kübler, A., \& Wänke, M. (1993). Awareness of the influence as a determinant of assimilation versus contrast. European Journal of Social Psychology, 23, 53-62.

Taylor, S. E. (1982). The availability bias in social perception and interaction. In D. Kahneman, P. Slovic, \& A. Tversky (Eds.), Judgment under uncertainty: Heuristics and biases (pp. 190-200). Cambridge, England: Cambridge University Press.

Tversky, A., \& Kahneman, D. (1973). Availability: A heuristic for judging frequency and probability. Cognitive Psychology, 5, 207-232.

Vaughn, L. A. (1997). Effects of expertise on use of recall experiences and recalled information for social judgments. Unpublished doctoral dissertation, University of Michigan, Ann Arbor.
Wänke, M., Bless, H., \& Biller, B. (1996). Subjective experience versus content of information in the construction of attitude judgments. Personality and Social Psychology Bulletin, 22, 1105-1113.

Wänke. M., Bohner, G., \& Jurkowitsch, A. (in press). There are many reasons to drive a BMW: Does imagined ease of argument generation influence attitudes? Journal of Consumer Research.

Wänke, M., Schwarz, N., \& Bless, H. (1995). The availability heuristic revisited: Experienced ease of retrieval in mundane frequency estimates. Acta Psychologica, 89, 83-90.

Winkielman, P., Schwarz, N., \& Belli, R. F. (1998). The role of ease of retrieval and attribution in memory judgments: Judging your memory as worse despite recalling more events. Psychological Science, 9, 46-48.

Wyer, R. S., \& Srull, T. K. (1989). Memory and cognition in its social context. Hillsdale, NJ: Lawrence Erlbaum Associates, Inc.

Zillman, D. (1978). Attribution and misattribution of excitatory reactions. In J. H. Harvey, W. Ickes, \& R. F. Kidd (Eds.), New directions in attribution research (Vol. 2, pp. 335-368). Hillsdale, NJ: Lawrence Erlbaum As'sociates, Inc. 